\title{
Melhoria da agregação do solo através do sistema plantio direto
}

\section{Soil particle aggregation improvement through no-tillage system}

\author{
Ademir Calegari ${ }^{1}$; Celso de Castro Filho ${ }^{1}$; João Tavares Filho ${ }^{2}$; \\ Ricardo Ralisch²; Maria de Fátima Guimarães ${ }^{2 *}$
}

\section{Resumo}

O objetivo deste trabalho foi verificar os efeitos de sistemas de manejo na melhoria do solo, principalmente quanto aos índices de agregação do solo. Em um Latosolo Vermelho distroférrico muito argiloso, na região oeste do Paraná, foram avaliados os efeitos do plantio direto, com e sem rotação de culturas, e o sistema convencional (uma aração e duas gradagens), em comparação com a área de floresta, na capacidade de agregação das partículas do solo. O delineamento experimental foi de blocos ao acaso com três repetições. Os sistemas avaliados foram: 1) sistema plantio direto, incluindo plantas de cobertura e rotação de culturas (PD integral); 2) sistema plantio direto sem rotação de culturas previamente definida (PD tradicional); 3) sistema convencional (uma aração + duas gradagens no momento da implantação das culturas); e uma área de mata, utilizada como referência do estado original do solo. As amostras de solo foram coletadas em todos os tratamentos, e os índices de agregação do solo determinados foram: o diâmetro médio ponderado (DMP), o diâmetro médio geométrico (DMG) e o índice de estabilidade de agregados (IEA\%). Também os teores de carbono orgânico foram determinados em todos tratamentos. Os maiores valores de carbono orgânico, e também IEA\%, DMP, DMG foram encontrados na área de floresta, quando comparada aos demais tratamentos. O sistema de plantio direto, incluindo plantas de cobertura e rotação de culturas (PD integral) contribuiu para o aumento dos teores de carbono orgânico do solo, e também para um aumento do IEA\%, DMP e DMG em ambos locais (Santa Helena e Entre Rios d'Oeste) em ambas profundidades do solo $(0-10$ e $0,10-0,20 \mathrm{~m})$. Os melhores índices de agregação observada são indicadores de qualidade no manejo desses solos. O sistema convencional provocou a dispersão das partículas de solo, e conseqüente diminuição dos índices de agregação (IEA \%), provocando queda nos níveis de matéria orgânica do solo quando comparado aos demais tratamentos, e também apresentou os menores índices de DMP e DMG, assim como a mais baixa concentração de agregados $>2,00 \mathrm{~mm}$.

Palavras-chave: Índices de agregação, matéria orgânica, cobertura de solo, carbono orgânico do solo, rotação de culturas

\begin{abstract}
The effects of no-tillage with and without crop rotation previously planned, conventional system including ploughing and disc harrowing on soil particles aggregation were evaluated and compared with native forest on an Red distroferric Oxisol with high clay content from western Paraná State. Soils were sampled from all treatments, adequately stored and soil aggregation indices determined were: the mean weight diameter (MWD), the geometric mean diameter (GMD) and the aggregate stability index (AS \%). Soil organic carbon was also determined for the different treatments. The results showed highest soil
\end{abstract}

\footnotetext{
1 Eng. Agr., Pesquisador Área de Solos - IAPAR, Rod. Celso G. CID, km 375, CEP-86001-970, Londrina-PR.

2 Professores Departamento de Agronomia -Universidade Estadual de Londrina, Londrina, PR.

* Autor para correspondência.
} 
organic carbon and also higher AS \%, MWD and GMD for native forest area compared to all other treatments. The no-tillage system, cover crops use and crop rotation contributed to increase soil organic carbon levels, and also AS \%, MWD and GMD in both localities and in both soil depths $(0,0-0,10 \mathrm{~m}$ and 0,10 $-0,20 \mathrm{~m}$ ). The conventional system, where soil are periodically disturbed provoking soil particles dispersion and soil aggregates collapse, promoted decreasing soil organic carbon levels compared to all other treatments, and also presented lower values for AS \%, MWD and GMD, as well lowest aggregates $>2,00 \mathrm{~mm}$.

Key words: Aggregation indices, organic matter, soil covering, soil organic carbon, crop rotation

\section{Introdução}

O contínuo processo de decomposição acelerada e acúmulo da matéria orgânica no solo está diretamente relacionado com o clima, o tipo de solo, o manejo e a qualidade dos resíduos adicionados (SANCHEZ et al., 1989). Assim, áreas intensamente cultivadas através do sistema convencional de produção, com revolvimento do solo e incorporação dos resíduos vegetais, tem contribuído para o processo de degradação das propriedades físicas, químicas e biológicas do solo. Já o sistema de plantio direto, com mobilização mínima, rotação de culturas e adoção das culturas de cobertura, promove maior produção de biomassa e recuperação do solo, conservação da água e ciclagem de nutrientes, viabilizando a agropecuária sustentável (CALEGARI et al., 1993; SCHOMBERG; FORD; HARGROVE, 1994; CHAVES; PAVAN; CALEGARI, 1997; FRANCHINI et al., 2001).

Os efeitos favoráveis das raízes sobre a formação, manutenção e tamanho dos agregados são conhecidos (CASTRO FILHO, 1988; CALEGARI; PAVAN, 1995). Resultados obtidos pôr Tisdall e Oades (1979) sugerem que as gramíneas, associadas à liberação de polissacarídeos por hifas de micorrizas, são mais eficientes no aumento da estabilidade de agregados do solo. Assim, as diferentes práticas de manejo, que propiciem maior e melhor enraizamento das culturas, poderão melhorar a parte física do solo e afetar diretamente os processos de agregação do solo.

O sistema plantio direto, ao manter os resíduos vegetais na superfície, tende a aumentar os teores de matéria orgânica do solo, melhorando a agregação das partículas em relação ao preparo convencional (CARPENEDO; MIELNICZUK, 1990). Estes agregados, maiores e menos densos, melhoram a aeração e aumentam a infiltração de água no solo (ROTH et al., 1986; CASTRO FILHO, 1988). Juntamente com a cobertura do solo, evitam o encrostamento superficial, reduzem os riscos de enxurradas e erosão e incrementam a biologia do solo (KLADIVKO, 1994). Já no preparo convencional, a ruptura dos agregados ocasionada pelo revolvimento do solo contribui para um maior ataque dos organismos, acelerando as perdas de Corgânico pela oxidação da matéria orgânica e pelos processos de erosão (OADES, 1984; MENDONÇA; ROWELL, 1994).

Ralisch (1999), realizando levantamento na região de Rolândia, PR, constatou que, dentre diferentes sistemas de produção adotados numa microbacia, apenas o sistema plantio direto considerado integral (incluindo plantas de cobertura e rotação de culturas) não apresentou indícios de deterioração do solo.

Este trabalho fez parte dos resultados das atividades desenvolvidas desde 1999 em um projeto em parceria entre Iapar-Itaipu-Prefeituras de Santa Helena e Entre Rios d'Oeste, em áreas de agricultores representativas dos diferentes sistemas de produção da Região Oeste do Paraná.

O objetivo deste trabalho foi avaliar o teor de carbono e a estabilidade de agregados em um Latossolo Vermelho distroférrico muito argiloso, submetido a diferentes sistemas de manejo.

\section{Material e Métodos}

O ensaio foi instalado em dois locais: município de Santa Helena, localizado à latitude de $24^{\circ} 55^{\prime} 41^{\prime \prime}$ S e longitude $54^{\circ} 21^{\prime} 19^{\prime \prime} \mathrm{W}$, com $260 \mathrm{~m}$ de altitude; 
município de Entre Rios do Oeste, localizado à latitude de $24^{\circ} 42^{\prime} 27^{\prime \prime} \mathrm{S}$ e longitude $54^{\circ} 16^{\prime} 12^{\prime \prime} \mathrm{W}$, com $261 \mathrm{~m}$ de altitude. A precipitação média anual é de $1700 \mathrm{~mm}$ e a temperatura média anual está entre 21 e $23^{\circ}$ C. O solo estudado foi classificado como Latossolo Vermelho distroférrico muito argiloso (EMBRAPA, 1999). As áreas escolhidas para estudo são contíguas, estando localizadas numa toposequência semelhante.

Os resultados das análises químicas e granulométrica das duas áreas no momento em que se iniciaram os trabalhos em 27/09/1999 são apresentados na Tabela 1.

Tabela 1. Resultados de análise química e granulométrica do solo LVd (0-0,15m), de Santa Helena e Entre Rios D’Oeste, no início dos estudos em 1999.

\begin{tabular}{|c|c|c|c|c|c|c|c|c|c|c|c|c|c|c|c|}
\hline \multirow[t]{2}{*}{ Local } & Argila & Silte & Areia & $\mathbf{P}$ & C & pH & Al & $\mathbf{A l}+\mathbf{H}$ & $\mathrm{Ca}^{++}$ & $\mathrm{Mg}^{++}$ & $\mathbf{K}^{+}$ & $\begin{array}{c}\text { Soma } \\
\text { de } \\
\text { bases }\end{array}$ & CTC & $\mathbf{V}$ & $\begin{array}{c}\text { Sat. } \\
\text { Al }\end{array}$ \\
\hline & \multicolumn{3}{|c|}{--------g kg ${ }^{-1}-\cdots---$} & $\mathbf{m g} /$ & $\mathbf{g} / \mathbf{d m}^{3}$ & & & \multicolumn{6}{|c|}{ - } & \multicolumn{2}{|c|}{$-\cdots \%$} \\
\hline $\begin{array}{l}\text { Santa } \\
\text { Helena }\end{array}$ & 74 & 18 & 8 & 23,0 & 17,7 & 5,4 & 0,0 & 4,27 & 6,80 & 2,44 & 0,33 & 9,57 & 13,84 & 69,04 & 0,0 \\
\hline $\begin{array}{c}\text { Entre } \\
\text { Rios } \\
\text { D’Oeste }\end{array}$ & 70 & 15 & 15 & 18,7 & 21,9 & 5,6 & 0,0 & 3,17 & 7,46 & 2,70 & 0,75 & 10,8 & 14,08 & 77,48 & 0,0 \\
\hline
\end{tabular}

CTC: capacidade de troca de cátions; V: saturação de bases

Os tratamentos foram: 1) sistema de plantio direto incluindo plantas de cobertura e rotação de culturas - PD integral, em Santa Helena: milho - Aveia preta + nabo + ervilha forrageira - soja - aveia preta + ervilha forrageira - milho; em Entre Rios do Oeste: soja - trigo - capim moha (Setaria italica) - soja aveia preta + tremoço branco - soja; 2) sistema de plantio direto sem rotação de culturas previamente definida (PD tradicional do agricultor), em Santa Helena: soja \% trigo - milho - nabo - milho, em Entre Rios do Oeste: soja - milho safrinha - soja trigo - soja; 3) sistema convencional (uma aração + duas gradagens no momento da implantação das culturas); 4) mata nativa, utilizada como referência do estado original do solo. O tratamento 3 consiste em uma área de sucessão soja-milho safrinha de mais de 10 anos, sendo que a área de Santa Helena vem sendo cultivada com mandioca há 4-5 anos.

Foram analisados duas profundidades de solo (0$0,1 \mathrm{~m}$ e $0,1-0,2 \mathrm{~m}$ ) em quatro tratamentos em parcelas de $1000 \mathrm{~m}^{2}$, sendo amostradas 3 repetições.
As amostras de solos dos tratamentos (Tabela 2) foram coletadas em maio de 2003, para análises físicas nas profundidades de 0-0,10 e 0,10-0,20m, nos quatro tratamentos, com três repetições. Em laboratório, trabalhou-se com 6 repetições por tratamento. As amostras para análise do teor de carbono foram também coletadas nesta época. A determinação da matéria seca das plantas de cobertura foram coletadas no período de florescimento pleno das plantas (3 repetições), momento em que as mesmas foram manejadas com herbicidas, para posterior implantação das culturas comerciais. As culturas comerciais, assim como as planas de cobertura, foram implantadas através de semeadura direta com máquina tratorizada. Após completarem o ciclo, foram colhidos os grãos das culturas comerciais (dados não apresentados). A matéria seca das culturas comerciais (soja e milho), foram obtidas com a coleta dos resíduos pós-colheita a campo (3 repetições). 
Tabela 2. Rotações de culturas e biomassa fornecidas pelos 2 sistemas de plantio direto em 5 safras. (1999-2000, 20002001, 2001-2002).

\begin{tabular}{llccccc}
\hline Local & Sistemas & $\begin{array}{c}\mathbf{9 9 / 0 0} \\
\text { Verão }\end{array}$ & $\begin{array}{c}\mathbf{2 0 0 0} \\
\text { Inverno }\end{array}$ & $\begin{array}{c}\mathbf{0 0 / 0 1} \\
\text { Verão }\end{array}$ & $\begin{array}{c}\mathbf{2 0 0 1} \\
\text { Inverno }\end{array}$ & $\begin{array}{c}\text { 01/02 } \\
\text { Verão }\end{array}$ \\
\hline \multirow{2}{*}{ Santa Helena } & PD integral & Milho & Ap+Np + Ef & Soja & Ap + Ef & Milho \\
& Mat. seca & $6,3 \mathrm{t} / \mathrm{ha}$ & $8,0 \mathrm{t} / \mathrm{ha}$ & $3,5 \mathrm{t} / \mathrm{ha}$ & $4,6 \mathrm{t} / \mathrm{ha}$ & $6,8 \mathrm{t} / \mathrm{ha}$ \\
& PD tradicional & Soja & Trigo & Milho & $\mathrm{Np}$ & Milho \\
& Mat. seca & $3,2 \mathrm{t} / \mathrm{ha}$ & $2,8 \mathrm{t} / \mathrm{ha}$ & $6,5 \mathrm{t} / \mathrm{ha}$ & $4,0 \mathrm{t} / \mathrm{ha}$ & $6,7 \mathrm{t} / \mathrm{ha}$ \\
\hline \multirow{2}{*}{$\begin{array}{l}\text { Entre Rios } \\
\text { d'Oeste }\end{array}$} & PD integral & Soja & Trigo/moha & Soja & $\mathrm{Ap}+\mathrm{Tb}$ & Soja \\
& Mat. Seca & $3,2 \mathrm{t} / \mathrm{ha}$ & $3,8 \mathrm{t} / \mathrm{ha}$ & $3,1 \mathrm{t} / \mathrm{ha}$ & $4,2 \mathrm{t} / \mathrm{ha}$ & $6,5 \mathrm{t} / \mathrm{ha}$ \\
& PD tradicional & Soja & Milho safrinha & Soja & Trigo & Soja \\
& Mat. Seca & $3,3 \mathrm{t} / \mathrm{ha}$ & $5,5 \mathrm{t} / \mathrm{ha}$ & $3,0 \mathrm{t} / \mathrm{ha}$ & $3,3 \mathrm{t} / \mathrm{ha}$ & $3,1 \mathrm{t} / \mathrm{ha}$ \\
\hline
\end{tabular}

Ap: aveia preta; Np: nabo pivotante; Ef: ervilha forrageira; Tb: tremoço branco.

Após a retirada das amostras de solo, foi efetuada a determinação da distribuição das classes de agregados pôr meio do tamisamento a úmido, utilizando-se peneiras de 2,0, 1,0,0,5 e 0,25mm, pelo método de Yoder (1936), modificado pôr Castro Filho, Muzilli e Podanoschi (1998). Os cálculos e determinações estatísticas das análises físicas foram realizadas através de um programa de computação proposto pôr Castro Filho (1988) e Castro Filho, Muzilli e Podanoschi (1998).

$\mathrm{O}$ tamisamento a úmido é feito em um recipiente cilíndrico onde se colocam três jogos de peneiras, para que cada amostra proveniente do campo seja analisada em triplicata, tirando-se uma média final que não deve ter coeficiente de variação superior a $10 \%$. O tamisador deve ter uma amplitude de 4-5 $\mathrm{cm}$. De oscilação e uma freqüência de 30 vezes pôr minuto. Cada conjunto no tamisador é constituído pôr peneiras com malhas de 2,0-1,0-0,5 e 0,25mm de diâmetro. As peneiras foram dispostas em escala decrescente no tamisador, sendo que a maior peneira ocupasse a parte superior do tamisador. O processo de tamisagem para cada amostra consistiu na separação de 3 sub-amostras de $80 \mathrm{~g}$ cada uma (peso do material úmido), uma para cada jogo de peneiras (repetições 1, 2 e 3 no laboratório) e uma para determinar a umidade e, assim, calcular o peso da amostra seca. Para cada jogo de peneiras, a amostra de agregados com $80 \mathrm{~g}$ foi colocada sobre a peneira de maior malha (superior), contendo um papel de filtro que está levemente em contacto com um filme de água para retenção da terra até que ela fosse saturada pôr capilaridade, durante 15 minutos. A saturação pôr capilaridade foi obtida pôr meio da elevação do nível de água do tamisador até que ela tocasse o papel de filtro. Depois de saturado, o papel era retirado com o auxílio de uma mangueira de água de baixa pressão retirando levemente o solo do papel para a peneira, após o que o tamisador era acionado pôr 10 minutos, com movimento vertical de 30 oscilações pôr minuto. $\mathrm{O}$ solo retido em cada peneira foi transferido para frascos com auxílio de jatos de água fracos dirigidos ao fundo da peneira e, em seguida, colocado na estufa para secagem, sendo posteriormente pesado. Quantificou-se o solo retido em cada peneira e, ainda, aquele que passou através da última peneira $(<0,25 \mathrm{~mm})$, para obtenção da seguinte classe de tamanho: 9,0-2,0; 2,0-1,0; 1,0-0,5; 0,5-0,25; < 0,25mm, cujos diâmetros médios serão (mm): 5,5; 1,5; 0,75; 0,375 e 0,125. Após a obtenção do peso de solo seco de cada classe de agregados 
(solo retido nas peneiras), calculou-se a média entre as três classes iguais. A classe de agregado de solo mais fino foi considerada aquela em que o solo passou pela peneira de $0,25 \mathrm{~mm}$ de malha, ficando disperso no tamisador. Seu valor, em gramas, foi computado, subtraindo-se o somatório do peso das outras classes de agregados do peso total da amostra seca. Com posse dos dados da distribuição dos agregados em cada amostra e tendo também suas respectivas porcentagens com relação ao peso seco da mesma, foi efetuado o cálculo dos índices de agregação do solo: DMP, DMG e IEA, da seguinte maneira:

\section{a) Diâmetro Médio Ponderado (DMP):}

$$
\mathrm{DMP}=\frac{\mathrm{n}}{\sum \mathrm{i}=1}(\mathrm{xi} . \mathrm{wi})
$$

onde: wi = proporção de cada classe em relação ao total; $\mathrm{xi}=$ diâmetro médio das classes $(\mathrm{mm})$;

\section{b)Diâmetro Médio Geométrico (DMG):}

$$
\mathrm{DMG}=\frac{\mathrm{N}}{\sum w p \cdot \log \mathrm{xi}}
$$

$\mathbf{I}=\mathbf{1}$

$$
\mathrm{DMG}=\frac{\mathrm{N}}{\sum \text { wi } \mathrm{I}=1}
$$

onde: $\mathrm{wp}=$ peso dos agregados de cada classe $(\mathrm{g})$;

c) Índice de Estabilidade de Agregados (IEA \%):

$$
\mathrm{IEA}=\frac{(\text { Peso da amostra seca }- \text { wp } 25-\text { areia })}{(\text { Peso da amostra seca }- \text { areia })} \times 100
$$

onde:

wp25 = peso dos agregados da classe $<0,25 \mathrm{~mm}$.
Em relação à quantidade de areia, testes anteriores foram feitos com $\mathrm{NaOH} 0,5 \mathrm{~mol} \mathrm{~L}^{-1}$ no tamisador para determinação de partículas maiores que 2,0 $\mathrm{mm}$ (cascalhos), considerando que as inferiores participam ativamente do processo de agregação. Encontrou-se a um valor de 1,02 g de concreções com diâmetro maior que 2,0 mm pôr amostra. Esse valor, apesar de ter sido usado, foi insignificante, porque o coeficiente de variação das amostras em triplicata no tamisador era maior que $5 \%$, superando o valor médio utilizado como peso de areia (CASTRO FILHO; MUZILLI; PODANOSCHI, 1998). Em solos originários de basalto, a maioria das partículas com o tamanho da areia consiste, na realidade, de 10-20\% de concreções de ferro e de 80-90\% de magnetita (EMBRAPA, 1984).

O carbono orgânico foi determinado através do método de Walkley black.

As parcelas experimentais foram de $1000 \mathrm{~m}^{2}$, e o delineamento experimental foi de blocos ao acaso com 3 repetições. Os resultados foram submetidos à análise de variância (teste $\mathrm{F}$ ), e as médias comparadas pelo teste de Tukey a $5 \%$.

\section{Resultados e Discussão}

A Tabela 3 mostra os resultados dos teores de Corgânico obtidos nos tratamentos em Santa Helena. Na camada de 0-0,1m houve um acúmulo maior de C-orgânico, quando comparada à camada de 0,1$0,2 \mathrm{~m}$. 
Tabela 3. Teores de carbono orgânico $\left(\mathrm{g} / \mathrm{dm}^{3}\right)$ para os diferentes sistemas de manejo do solo e mata em duas profundidades para a área de Santa Helena-PR. (Média de 3 repetições).

\begin{tabular}{|c|c|c|}
\hline \multirow{2}{*}{ Tratamentos } & \multicolumn{2}{|l|}{ Profundidade } \\
\hline & $0-0,1 \mathrm{~m}$ & $0,1-0,2 m$ \\
\hline & C org. $\left(\mathrm{g} / \mathrm{dm}^{3}\right)$ & \\
\hline Mata & $29,42 \mathrm{~A}^{*}$ & $21,42 \mathrm{~A}$ \\
\hline PD integral & $24,97 \quad \mathrm{~B}$ & $18,38 \mathrm{~A}$ \\
\hline PD tradicional & $23,02 \quad \mathrm{~B}$ & $18,44 \mathrm{~A}$ \\
\hline Convencional & 19,05 & $18,61 \mathrm{~A}$ \\
\hline
\end{tabular}

*Médias seguidas por letras iguais na coluna, não diferem entre si pelo teste de Tukey a 5\% de probabilidade.

Ainda na profundidade $0-0,1 \mathrm{~m}$, em ambos locais: Santa Helena e Entre Rios d'Oeste (Tabelas 3 e 4), a área com mata foi a que apresentou os maiores valores de C-orgânico, diferindo dos demais tratamentos. $\mathrm{Na}$ área de Entre Rios, quando os diferentes sistemas de manejo são comparados, os valores médios de carbono orgânico do plantio direto integral e tradicional são mais próximos aos do solo da mata, apesar de não haver diferença estatística entre os tratamentos. Em Santa Helena na camada de $0-0,1 \mathrm{~m}$, o convencional acumulou o menor teor de carbono comparado aos demais tratamentos, e o PD integral e tradicional não diferiram entre si. Em Santa Helena, na camada de 0,1 - 0,2m, não houve diferença significativa entre os tratamentos. No sistema convencional, devido ao contínuo revolvimento e incorporação dos resíduos vegetais, ocorreu uma maior desagregação das partículas e aceleração no processo de mineralização da matéria orgânica e, consequentemente, menores valores de carbono orgânico, principalmente na camada superficial do solo. Na área de Entre Rios d'Oeste (Tabela 4), na profundidade de $0,1-0,2 \mathrm{~m}$ a mata apresentou o maior teor de carbono orgânico e diferiu de todos os demais tratamentos. O convencional em ambas profundidades, apresentou os menores teores de carbono orgânico do solo. Considerando que o sistema convencional degrada a matéria orgânica, os tratamentos em que não ocorre revolvimento do solo, estão recuperando os teores de C-orgânico sendo que no PD esta recuperação está sendo maior e mais próxima da condição de mata.

Tabela 4. Teores de carbono orgânico $\left(\mathrm{g} / \mathrm{dm}^{3}\right)$ para os diferentes sistemas de manejo do solo e mata em duas profundidades para a área de Entre Rios d'Oeste-Pr. (Média de 3 repetições).

Tratamentos

\section{0-0,1}

$\begin{array}{ll}27,59 & \text { A } \\ 22,44 & \text { B } \\ 21,55 & \text { B } \\ 20,97 & \text { B }\end{array}$

Mata

PD integral

PD tradicional

Convencional

Médias seguidas por letras iguais, na coluna, não diferem entre si pelo teste de Tukey a $5 \%$ de probabilidade.

\begin{tabular}{l}
$21,83 \mathrm{~A}$ \\
$17,29 \mathrm{BC}$ \\
$18,67 \mathrm{~B}$ \\
$16,57 \quad \mathrm{C}$ \\
\hline
\end{tabular}

$\begin{array}{ll}21,83 & \mathrm{~A} \\ 17,29 & \mathrm{BC} \\ 18,67 & \mathrm{~B} \\ 16,57 \quad \mathrm{C}\end{array}$

\section{Profundidade (m)}

C org. $\left(\mathrm{g} / \mathrm{dm}^{3}\right)$

\section{0,1-0,2}


Independentemente da profundidade do solo, em ambos locais, Santa Helena e Entre Rios d'Oeste (Tabela 5), o solo da mata foi sempre o que apresentou os maiores teores de carbono orgânico, enquanto o PD integral não diferiu do PD tradicional, mas foi estatisticamente superior ao convencional na profundidade de 0-0,1m. Por outro lado, o PD tradicional, sem uso de plantas de cobertura e rotação de culturas, não diferiu do sistema convencional. Assim, o não preparo do solo, aliado à adição constante de resíduos ao solo, foi responsável por elevar os teores de carbono orgânico do solo.

Tabela 5. Teores de carbono orgânico $\left(\mathrm{g} / \mathrm{dm}^{3}\right)$ para os diferentes sistemas de manejo do solo, independente da profundidade, para os dois locais estudados. (Média de 3 repetições).

\section{Locais}

\section{Tratamentos}

Santa Helena

\begin{tabular}{llrll} 
Mata & 25,42 & $\mathrm{~A}^{*}$ & \multicolumn{2}{c}{$24,72 \mathrm{~A}$} \\
PD integral & 21,68 & $\mathrm{~B}$ & 20,11 & $\mathrm{~B}$ \\
PD tradicional & 20,73 & BC & 19,87 & BC \\
Convencional & 18,83 & C & 18,77 & C \\
\hline
\end{tabular}

* Média seguida por letras iguais, na coluna, não diferem entre si pelo teste de Tukey a 5\% de probabilidade.

Na Tabela 6 observa-se, para Santa Helena, que o sistema convencional possui maior quantidade de agregados menores $(<0,25 \mathrm{~mm})$ nas duas profundidades, conseqüência de uma maior pulverização do solo através dos preparos, resultados em concordância com Roth et al. (1986) e Castro Filho, Muzilli e Podanoschi (1998). Por outro lado, o solo da área de mata, na profundidade 0 - $0,1 \mathrm{~m}$ não diferiu de ambos PD (integral e tradicional), sendo superior ao convencional, na classe maior de agregados $(>2,00 \mathrm{~mm})$. Na camada $0,1-0,2 \mathrm{~m}$ o convencional diferiu de todos os tratamentos apenas no menor tamanho de agregados, enquanto que nas demais classes não houve diferenças entre os tratamentos.

Tabela 6. Distribuição das classes de tamanho de agregados nos diferentes sistemas em duas profundidades. Santa Helena-PR, 2003.

\begin{tabular}{|c|c|c|c|c|c|}
\hline \multirow{3}{*}{ Tratamento } & \multicolumn{5}{|c|}{ Classe de tamanho de agregados $(\mathrm{mm})$} \\
\hline & $<0,25$ & $0,25-0,50$ & $0,50-1,00$ & $1,00-2,00$ & $>2,00$ \\
\hline & \multicolumn{5}{|c|}{$\mathbf{0 - 0 , 1 ~ m ~}$} \\
\hline PD tradicional & $3,62 \mathrm{~B}^{*}$ & $3,94 \mathrm{~A}$ & $12,16 \mathrm{~A}$ & $15,63 \mathrm{~A}$ & $32,80 \mathrm{~A}$ \\
\hline Mata & $3,03 \mathrm{~B}$ & $8,01 \mathrm{~A}$ & $8,07 \mathrm{~A}$ & $12,32 \mathrm{~A}$ & $33,08 \mathrm{~A}$ \\
\hline PD integral & $5,27 \mathrm{~B}$ & $5,91 \mathrm{~A}$ & $13,87 \mathrm{~A}$ & $12,63 \mathrm{~A}$ & $29,34 \mathrm{AB}$ \\
\hline \multirow[t]{2}{*}{ Convencional } & $13,48 \mathrm{~A}$ & $9,57 \mathrm{~A}$ & $13,74 \mathrm{~A}$ & $12,59 \mathrm{~A}$ & $17,32 \mathrm{~B}$ \\
\hline & \multicolumn{5}{|c|}{$0,1-0,2 \mathrm{~m}$} \\
\hline PD tradicional & $5,66 \mathrm{~B}$ & $7,33 \mathrm{~A}$ & $10,72 \mathrm{~A}$ & $14,80 \mathrm{~A}$ & $29,45 \mathrm{~A}$ \\
\hline Mata & $4,32 \mathrm{~B}$ & $4,61 \mathrm{~A}$ & $7,40 \mathrm{~A}$ & $11,52 \mathrm{~A}$ & $35,44 \mathrm{~A}$ \\
\hline PD integral & $5,86 \mathrm{~B}$ & $4,37 \mathrm{~A}$ & $8,40 \mathrm{~A}$ & $13,73 \mathrm{~A}$ & $34,45 \mathrm{~A}$ \\
\hline Convencional & $13,29 \mathrm{~A}$ & $7,11 \mathrm{~A}$ & $9,25 \mathrm{~A}$ & $10,82 \mathrm{~A}$ & $23,20 \mathrm{~A}$ \\
\hline
\end{tabular}

* Médias seguidas por letras iguais, na coluna, dentro de cada profundidade, não diferem entre si pelo teste de Tukey a $5 \%$ de probabilidade. 
Em Entre Rios d'Oeste (Tabela 7), houve em geral uma maior formação de agregados grandes $(>2,00 \mathrm{~mm})$ em relação à Santa Helena, possivelmente devido à uma maior adição de resíduos orgânicos ao longo dos anos. Foi também encontrada uma maior concentração de agregados pequenos $(<0,25 \mathrm{~mm})$ no sistema convencional, diferindo dos demais tratamentos em ambas profundidades. Apesar da menor concentração dos agregados grandes $(>2,00 \mathrm{~mm})$ no convencional, não foram observadas diferenças entre os tratamentos. As classes intermediárias de agregados não diferiram entre si nos diferentes tratamentos.

Tabela 7. Distribuição das classes de tamanho de agregados nos diferentes sistemas em duas profundidades. Entre Rios d'Oeste - PR, 2003.

\begin{tabular}{cccccc}
\hline \multirow{2}{*}{ Tratamento } & \multicolumn{5}{c}{ Classe de tamanho de agregados (mm) } \\
\cline { 2 - 6 } & $\mathbf{2 0 , 2 5}$ & $\mathbf{0 , 2 5 - 0 , 5 0}$ & $\mathbf{0 , 5 0 - 1 , 0 0}$ & $\mathbf{1 , 0 0 - 2 , 0 0}$ & $>\mathbf{2 , 0 0}$ \\
\cline { 2 - 6 } PD tradicional & $3,44 \mathrm{~B}^{*}$ & $5,66 \mathrm{~A}$ & $10,19 \mathrm{~A}$ & $14,19 \mathrm{~A}$ & $38,53 \mathrm{~A}$ \\
Mata & $2,99 \mathrm{~B}$ & $6,60 \mathrm{~A}$ & $7,95 \mathrm{~A}$ & $8,90 \mathrm{~A}$ & $39,09 \mathrm{~A}$ \\
PD integral & $3,22 \mathrm{~B}$ & $3,31 \mathrm{~A}$ & $7,24 \mathrm{~A}$ & $14,35 \mathrm{~A}$ & $40,48 \mathrm{~A}$ \\
Convencional & $7,74 \mathrm{~A}$ & $5,99 \mathrm{~A}$ & $7,87 \mathrm{~A}$ & $9,77 \mathrm{~A}$ & $32,86 \mathrm{~A}$ \\
\hline \multirow{2}{*}{ PD tradicional } & $3,75 \mathrm{~B}$ & $3,36 \mathrm{~A}$ & $5,39 \mathrm{~A}$ & $14,68 \mathrm{~A}$ & $40,24 \mathrm{~A}$ \\
Mata & $3,72 \mathrm{~B}$ & $3,94 \mathrm{~A}$ & $9,08 \mathrm{~A}$ & $8,18 \mathrm{~A}$ & $39,51 \mathrm{~A}$ \\
PD integral & $4,59 \mathrm{~B}$ & $6,34 \mathrm{~A}$ & $8,75 \mathrm{~A}$ & $11,55 \mathrm{~A}$ & $38,84 \mathrm{~A}$ \\
Convencional & $7,28 \mathrm{~A}$ & $4,71 \mathrm{~A}$ & $6,46 \mathrm{~A}$ & $8,60 \mathrm{~A}$ & $36,09 \mathrm{~A}$ \\
\hline
\end{tabular}

* Médias seguidas por letras iguais, na coluna, dentro de cada profundidade, não diferem entre si pelo teste de Tukey a $5 \%$ de probabilidade.

As Figuras 1 e 2 apresentam os dados do IEA, que representam que, quanto menor a concentração de agregados $<0,25 \mathrm{~mm}$, maior será o IEA. Os maiores valores foram encontrados na área de mata e PD (integral e tradicional) que não diferiram entre si, diferindo apenas do convencional em ambos locais (Santa Helena e Entre Rios d'Oeste) e em ambas profundidades (0-0,1 e 0,1-0,2m). A área com mata foi a que apresentou os maiores valores devido à adição constante de resíduos vegetais, assim como ao não revolvimento do solo, o que repercutiu também no aumento dos teores de carbono orgânico em relação aos demais tratamentos, semelhante aos resultados obtidos por Castro Filho, Muzilli e Podanoschi (1998). Quanto maiores os teores de carbono orgânico obtidos, maiores foram os índices de agregação total do solo. A área de plantio direto, incluindo rotação de culturas e plantas de cobertura (PD integral), com um maior aporte de resíduos orgânicos ao longo dos anos (Tabela 2), apresentou os valores mais próximos aos da mata, embora não tenha se diferenciado estatisticamente da mata e da área tradicional do produtor, demonstrando assim que através de sistemas adequadamente conduzidos é possível manter o solo em condições físicas de agregação mais próximas à condição de mata (CASTRO FILHO; MUZILLI; PODANOSCHI, 1998; CARPENEDO; MIELCNIZUK, 1990; KLADIVKO, 1994). O sistema de plantio direto tradicional, embora não venha sendo conduzido com 
rotação e plantas de cobertura previamente planejado, demonstrou que após oito anos sem preparo e com adição anual de resíduos na superfície, não prejudica a condição de agregação do solo; ao contrário do convencional, que apresentou os menores valores de agregação. Os resultados observados em Entre Rios d'Oeste foram semelhantes aos de Santa Helena, ou seja, os valores obtidos nas áreas de mata, PD integral e tradicional não diferiram entre si, e foram superiores ao convencional, que por sua vez apresentou diferenças significativas em relação aos demais tratamentos.

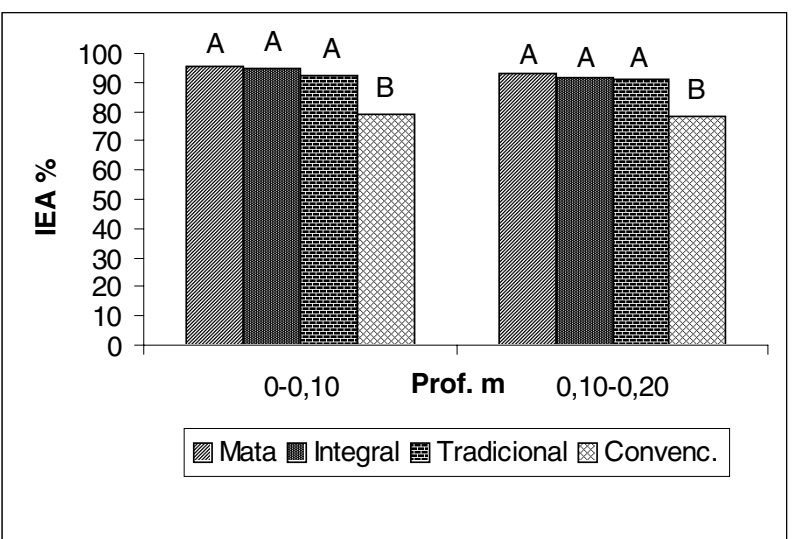

Figura 1. Índice de estabilidade de agregados em diferentes sistemas de manejo do solo. Prof. 0-0,10m e 0,10-0,20m, Santa Helena - PR, 2003. Médias seguidas por letras iguais, dentro de cada profundidade, não diferem entre si pelo teste de Tukey a 5\% de probabilidade.

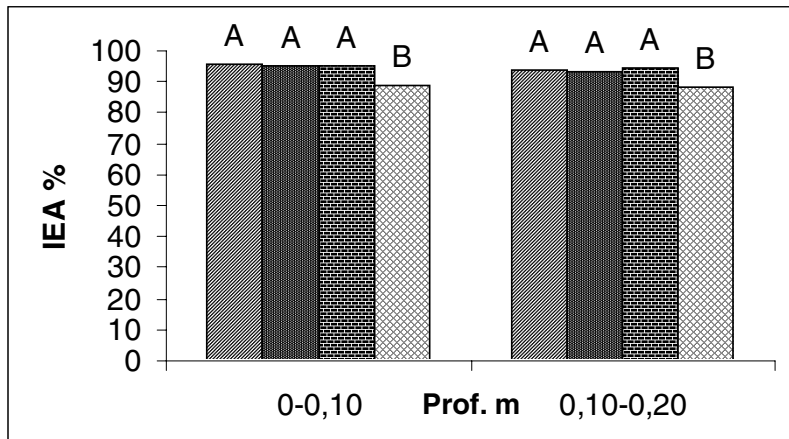

Mata 酒 Integral 圈 Tradicional 图Convenc

Figura 2. Índice de estabilidade de agregados em diferentes sistemas de manejo do solo. Prof. 0-0,10m e 0,10-0,20m, Entre Rios -PR, 2003. Médias seguidas por letras iguais, dentro de cada profundidade, não diferem entre si pelo teste de Tukey a 5\% de probabilidade.
No sistema convencional o solo é intensamente revolvido, provocando efeitos indesejáveis tais como: desagregação das partículas de solo, aceleração na decomposição do carbono orgânico e os menores índices de estabilidade de agregados em relação aos demais (OADES, 1984; MENDONÇA; ROWELL, 1994). Isto comprova a ação de desagregação do solo exercida pelas operações de revolvimento (preparo convencional), enquanto que o mínimo distúrbio do solo, representado pelo plantio direto, promove uma maior agregação das partículas, evitando riscos de erosão e maior proteção da matéria orgânica do solo.

O diâmetro médio ponderado (DMP), que indica a percentagem de agregados grandes retidos nas peneiras com malhas maiores, apresentou os maiores valores nas áreas que receberam mais resíduos na superfície sem revolvimento do solo (mata e os dois sistemas de plantio direto), sendo significativamente superior apenas ao convencional na camada de 0,10,2m (Figura 3). Por outro lado, o sistema convencional, pelo maior distúrbio na superfície teve um menor número de agregados grandes e, consequentemente um menor DMP, mesma tendência foi observada em Entre Rios. Em Entre Rios (Figura 4), embora o convencional tenha apresentado os menores valores, nenhuma diferença foi encontrada quando comparados todos os tratamentos.

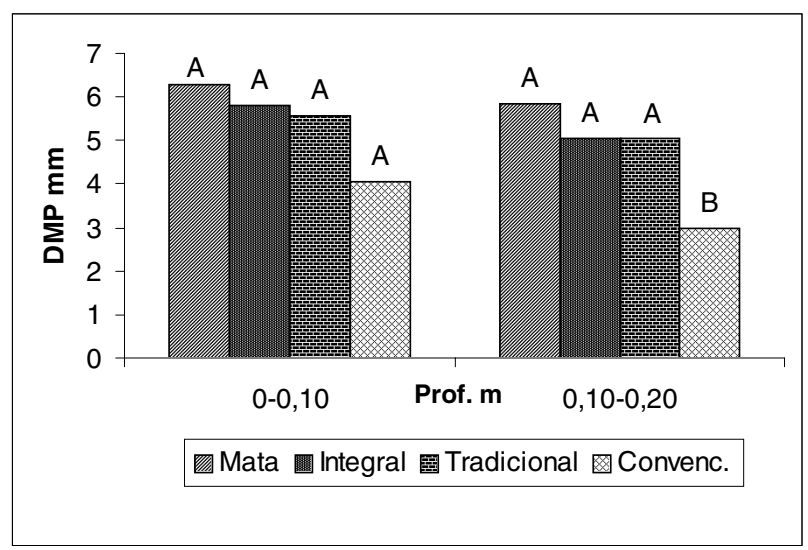

Figura 3. Diâmetro Médio Ponderado em diferentes sistemas de manejo do solo. Prof. 0-0,1 e 0,1-0,2 m, Santa Helena-PR, 2003. Médias seguidas por letras iguais, dentro de cada profundidade, não diferem entre si pelo teste de Tukey a $5 \%$ de probabilidade. 


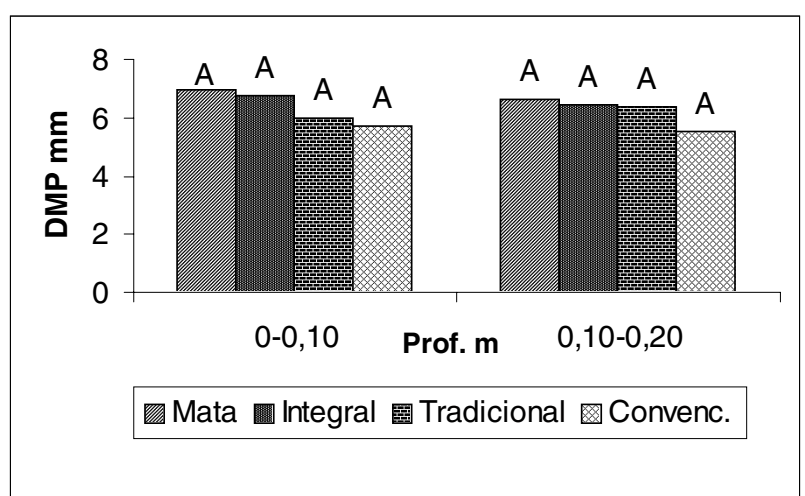

Figura 4. Diâmetro Médio Ponderado em diferentes sistemas de manejo do solo. Prof. 0-0,1 e 0,1-0,2 m, Entre Rios -PR, 2003. Médias seguidas por letras iguais, dentro de cada profundidade, não diferem entre si pelo teste de Tukey a 5\% de probabilidade.

Com relação ao diâmetro médio geométrico (DMG) (Figuras 5 e 6), a mesma tendência foi observada tanto em Santa Helena quanto Entre Rios d'Oeste, onde o solo da mata e o PD (integral e tradicional) foram os que mais contribuíram para o aumento do tamanho médio da classe dominante de agregados e não diferiram entre si em ambas profundidades $(0-0,1$ e $0,10-0,2 \mathrm{~m})$; enquanto o tratamento convencional apresentou os menores valores e diferenças significativas em relação a todos os demais tratamentos.

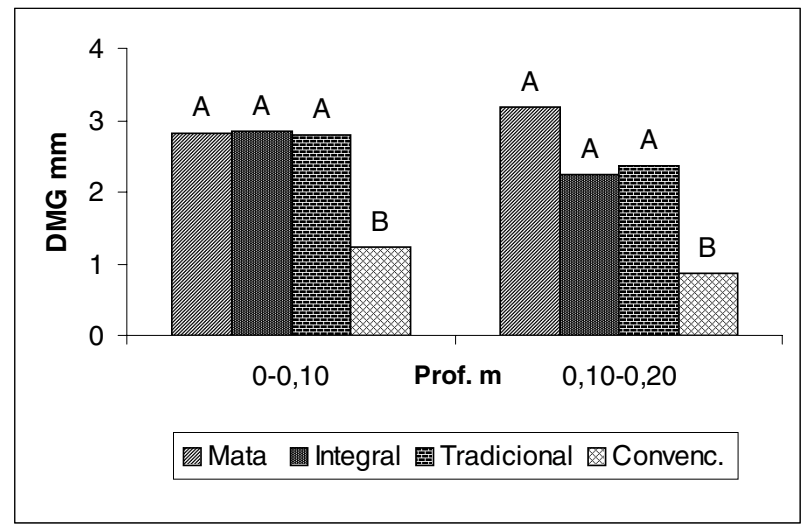

Figura 5. Diâmetro Médio Geométrico em diferentes sistemas de manejo do solo. Prof. 0-0,1 e 0,1-0,2 m, Santa Helena-PR, 2003. Médias seguidas por letras iguais, dentro de cada profundidade, não diferem entre si pelo teste de Tukey a $5 \%$ de probabilidade

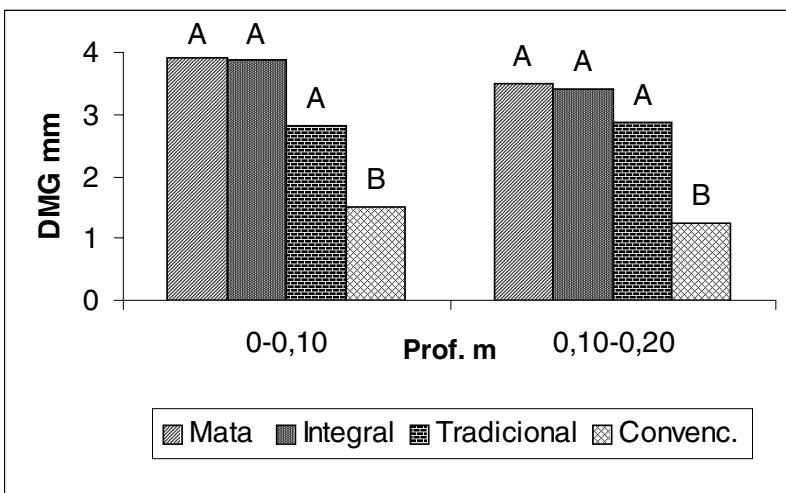

Figura 6. Diâmetro Médio Geométrico em diferentes sistemas de manejo do solo. Prof. 0-0,1 e 0,1-0,2 m, Entre Rios -PR, 2003. Médias seguidas por letras iguais, dentro de cada profundidade, não diferem entre si pelo teste de Tukey a $5 \%$ de probabilidade.

Vários experimentos de longa duração, conduzidos em diferentes regiões, têm mostrado os efeitos benéficos do acúmulo de resíduos orgânicos na superfície do solo pelo sistema de plantio direto, onde, além de o solo não ser revolvido é complementado por bons sistemas de rotação de culturas e uso adequado de plantas de cobertura (SIDIRAS; PAVAN, 1985; SANCHEZ et al., 1989; SÁ, 1993; SCHOMBERG; FORD; HARGROVE, 1994; REICOSKY et al., 1995; FRANCHINI et al., 2001; AMADO et al., 2001; CALEGARI, 2002).

\section{Conclusões}

O sistema de plantio direto recupera o teor de carbono orgânico do solo e, quando complementado com sistema de rotação de culturas e plantas de cobertura, antecipa esta recuperação, promovendo melhoria do estado de agregação.

O sistema convencional contribuiu para diminuição dos teores de carbono orgânico do solo, menores valores de IEA, DMP e DMG, além de uma menor $\%$ de agregados $>2,00 \mathrm{~mm}$. 


\section{Referências}

AMADO, T. J. C.; BAYER, C.; ELTZ, F. L. F.; BRUM, A. C. R. Potencial de culturas de cobertura em acumular carbono e nitrogênio no solo no plantio direto e a melhoria da qualidade ambiental. Revista Brasileira de Ciência do Solo, Campinas, v.25, p.189-197, 2001.

CALEGARI, A. The spread and benefits of no-till Agriculture in Paraná State, Brazil. In: UPHOFF, N. Agroecological innovations: increasing food production with participatory development. London: Earthscan, 2002. p.187-202.

CALEGARI, A.; MONDARDO, A.; BULISANI, E. A.; WILDNER, L. D. O P.; COSTA, M. B. B.; ALCÂNTARA, P. B.; MIYASAKA, S.; AMADO, T. J. C. Adubação verde no sul do Brasil. 3. ed. Rio de Janeiro: AS-PTA, 1993.

CALEGARI, A.; PAVAN, M. A. Efeitos da rotação de milho com adubos verdes de inverno na agregação do solo. Arquivos de Biologia e Tecnologia, Curitiba, v.38, n.1, p.45-53, mar. 1995.

CARPENEDO, V.; MIELNICZUK, J. Estado de agregação e qualidade de agregados de Latossolos Roxos, submetidos a diferentes sistemas de manejo. Revista Brasileira de Ciência do Solo, Campinas, v.14, p.99-105, 1990.

CASTRO FILHO, C. Effects of liming on characteristics of a Brazilian Oxisol at three levels of organic matter as related to erosion. 1988. Dissertação (Tese) - State University, Columbus, Ohio.

CASTRO FILHO, C.; MUZILLI, O.; PODANOSCHI, A. L. Estabilidade dos agregados e sua relação com o teor de carbono orgânico num Latossolo roxo distrófico, em função de sistemas de plantio, rotação de culturas e métodos de preparo das amostras. Revista Brasileira de Ciência do Solo, Campinas, v.22, p.527-538, 1998.

CHAVES, J. C. D.; PAVAN, M. A.; CALEGARI, A. Adição de matéria seca e nutrientes através da utilização de plantas para cobertura em culturas perenes e seus efeitos sobre a reação do solo. Arquivos de Biologia e Tecnologia, Curitiba, v.40, n.1, p.47-55, mar. 1997.

EMBRAPA. Sistema brasileiro de classificação de solos. Rio de Janeiro: Embrapa/CNPSo, 1999.

EMBRAPA. Levantamento de reconhecimento dos solos do estado do Paraná. Curitiba: Embrapa/SNLCS, 1984. 2v. (Boletim Técnico, 57).

FRANCHINI, J. C.; GONZALEZ-VILA, F. J.; CABRERA, F.; MIYAZAWA, M.; PAVAN, M. A. Rapid transformations of plant water-soluble organic compounds in relation to cation mobilization in an acid Oxisol. Plant and Soil, The Hague, v.231, p.55-63, 2001.
KLADIVKO, E. J. Residue effect on soil physical properties. In: . Managing agricultural residues. Florida: Lewis Publisher, 1994. p.121-141.

MENDONÇA, E. S.; ROWELL, D. L. Dinâmica do alumínio e de diferentes frações orgânicas de um Latossolo argiloso sob cerrado e soja. Revista Brasileira de Ciência do Solo, Campinas, v.18, p.295-303, 1994.

OADES, J. M. Soil organic matter and structural stability: mechanisms and implications for management. Plant and Soil, The Hague, v.76, p.319-337, 1984.

RALISCH, R Análise comparativa do desempenho de três equipamentos de preparo do solo na descompactação de um Latossolo roxo. 1999. Tese (Doutorado em Agronomia) - Universidade Estadual Paulista Júlio de Mesquita Filho, Botucatu.

REICOSKY, D. C.; KEMPER, W. D.; LANGDALE, G. W.; DOUGLAS, C. L.; RASMUSSEN, P. E. Soil organic matter changes resulting from tillage and biomass production. Journal of Soil and Water Conservation, Ankeny, v.50, n.3, p.253-261, May-June 1995

ROTH, C. H.; PAVAN, M. A.; CHAVES, J. C. D.; MEYER, B.; FREDE, H. G. Efeito das aplicações de calcário e gesso sobre a estabilidade de agregados e infiltrabilidade de água em um Latossolo Roxo cultivado com cafeeiros. Revista Brasileira de Ciência do Solo, Campinas, v.10, p.163-166, 1986.

SÁ, J. C. M. Manejo da fertilidade do solo no plantio direto. Castro-Pr: Fundação ABC, Aldeia Norte, 1993.

SANCHEZ, P. A.; PALM, C. A.; SZOTT, L. T.; CUEVAS, E.; LAL, R. Organic input management in tropical agroecosystems. In: COLEMAN, D. C.; OADES, J. M.; UEHARA, G. (Ed.). Dynamic of soil organic matter in Tropical Ecosystems. Maui, Hawaii: University of Hawaii, 1989.

SCHOMBERG, H. H.; FORD, P. B.; HARGROVE, W. L. Influence of crop residues on nutrient cycling and soil chemical properties. In: PAUL, W. (Ed.). Managing agricultural residues. Florida: Lewis Publisher, CRC Press, 1994. p.99-121

SIDIRAS, N.; PAVAN, M.A. Influência do sistema de manejo de solo no seu nível de fertilidade. Revista Brasileira de Ciência do Solo. Campinas, v.9, n3, p.249254, set./dez. 1985.

TISDALL, J. M.; OADES, J. M. Stabilization of soil aggregates by the root system of ryegrass. Australian Journal Soil Research, Alexandria, v.17, p.429-441, 1979.

YODER, R. E. A direct method of aggregate analysis of soils and a study of the physical nature of erosion losses. Journal of America Society Agronomy, Madison, v.28, p.337-351, 1936. 